\title{
Psychological assessments before and after treatment of early puberty in adopted children
}

\author{
D Mul $^{1}$, HJM Versluis-den Bieman ${ }^{2}$, FME Slijper ${ }^{2}$, W Oostdijk ${ }^{1,3}$, JJJ Waelkens ${ }^{4}$ and SLS Drop ${ }^{1}$ \\ Departments of Endocrinolog $y^{1}$ and Child and Adolescent Psychiatry ${ }^{2}$, University Hospital Rotterdam/Sophia Children's Hospital, \\ Rotterdam; Department of Pediatrics ${ }^{3}$, Leiden University Medical Centre, Leiden; Department of Pediatrics ${ }^{4}$, Catharina Hospital, \\ Eindhoven, The Netherlands
}

Mul D, Versluis-den Bieman HJM, Slijper FME, Oostdijk W, Waelkens JJJ, Drop SLS. Psychological assessments before and after treatment of early puberty in adopted children. Acta Pædiatr 2001; 90: 965-971. Stockholm. ISSN 0803-5253

Early puberty is frequently observed in adopted children. This randomized trial treated 30 adopted children with early puberty and short stature with either gonadotropin-releasing hormone agonist $(\mathrm{GnRHa})$ alone or in combination with growth hormone $(\mathrm{GH})$ for $3 \mathrm{y}$. Before the start of treatment (T1) in the trial and at discontinuation (T2) the children and their parents underwent a psychological evaluation. At the start of treatment the children did not have increased levels of behavioural or emotional problems as assessed by the Child Behaviour Checklist (CBCL). During treatment the CBCL scores did not increase. Self-perception of the children appeared to be normal, and after $3 \mathrm{y}$ a significantly higher score for acceptance by peers was observed. At T1, an overestimation of future height was present in $80 \%$ of the children and $17 \%$ of the parents. Lower family stress was observed at $\mathrm{T} 1$ and $\mathrm{T} 2$ compared with reference values. Intelligence quotient levels decreased significantly during treatment. The findings are discussed with reference to the reported levels of behavioural and emotional problems in adopted children and the psychosocial effects of precocious puberty.

Conclusion: This psychological evaluation did not reveal any consistent abnormalities in adopted children with early puberty. Treatment with GnRHa with or without GH did not increase emotional and behavioural problems in adopted children, nor was their self-perception decreased.

Key words: Adopted children, early puberty, GnRH agonist, growth hormone, psychology

D Mul, Erasmus University Medical Centre/Sophia Children's Hospital, Subdiv. Endocrinology (Sp 3429), PO Box 2060, NL-3000 CB Rotterdam, The Netherlands (Fax. +31 104636811 , e-mail.mul@alkg.azr.nl)

Early puberty is frequently seen in foreign-born adopted children (1-3). No clear explanation is available for the occurrence of early puberty. It may be hypothesized that improvements in nutritional status and socioeconomic situation compared with those in the country of origin result in an accelerated maturation of neuroendocrine structures, especially during a specific critical period after birth.

The effects of early puberty are well known: psychosocial distress and emotional problems (4-6) in addition to a decreased final height (7). In adopted children psychosocial evaluation has revealed increased parent-reported emotional and behavioural problems compared with non-adopted peers $(8,9)$. It may be assumed therefore that adopted children with early puberty are particularly at risk for emotional and behavioural problems. These problems could be attributed to early pubertal development, short stature and the adoption status.

The pubertal development in central precocious puberty or early puberty may be arrested effectively by gonadotropin-releasing hormone agonist (GnRHa) administration.

This study investigated the effect of puberty-delaying treatment with GnRHa alone or in combination with recombinant human growth hormone $(\mathrm{GH})$ to promote growth in adopted children with early puberty. The aim was to evaluate the psychological effects of early puberty and short stature, as well as the effects of the treatment. This paper describes the results of psychological assessments before (T1) and after treatment (T2). The evaluation of motivation for treatment and the effects of treatment on growth and puberty will be reported separately.

\section{Patients and methods}

The children in this study originated from India, Sri Lanka, Colombia and Korea, and had been adopted by Dutch parents. The children developed early puberty, defined as pubertal development between 7 and $10 \mathrm{y}$ of 
age in girls and between 8 and $11 \mathrm{y}$ in boys. Puberty was characterized in girls by breast development and/or menarche, and in boys by testicular enlargement $(\geq 4 \mathrm{ml})$. In both sexes the physical signs were accompanied by a pubertal rise in gonadotropins in a GnRH stimulation test. An X-ray of the left hand was taken to assess bone age (BA). The predicted adult height $(\mathrm{PAH})$ was calculated on the basis of height and BA. For inclusion in the study PAH had to be below the third percentile of Dutch children for sex (10). After the assessment of motivation for treatment, 30 patients $(3 \mathrm{M}, 27 \mathrm{~F})$ were eligible candidates for the study and entered in the treatment protocol: 12 from Sri Lanka, 9 from India, 7 from Colombia and 2 from South Korea. Two girls had already had their menarche, one in each treatment group.

The children in this study were treated for $3 \mathrm{y}$ with either the GnRHa triptorelin (Decapeptyl ${ }^{\mathbb{R}}$ ) alone (group A) or in combination with human recombinant GH (Genotropin ${ }^{\mathrm{R}}$ ) (group B). A physician or nurse administered the GnRHa every $28 \mathrm{~d}$ by an intramuscular (i.m.) injection; GH was administered every day by subcutaneous (s.c.) injection at home by the patient or one of the parents.

\section{Change in design}

In the original study design a third arm with untreated children was scheduled as a control group. It was decided to omit this control group from the study design after it appeared that the parents of all patients who were randomized in the untreated control group refused further participation in the study as GnRHa treatment could be obtained elsewhere. This article describes the results of the patients entering into the treatment protocol.

\section{T1 data collection}

Before randomization for group A or B, a psychological assessment (T1) was performed including the following instruments.

Child Behaviour Checklist (CBCL). The CBCL is a standardized instrument to obtain parents' reports of competence and problem behaviour of their child (11). It consists of 20 competence items and 120 problem items. Competence ratings were scored on three competence scales: activities, social and school, and on a total competence score. The problem items that describe the child are summarized in a score for internalizing (e.g. withdrawn, anxious/depressed) and externalizing (e.g. aggressive, delinquent) problems, and a total problem score. The reliability and discriminative validity of the Dutch translation have been established (12). Reference values for adopted children in the Dutch population were used for comparison (13). For the Dutch references the normative values for ages 4-11 y were used and for the references of adopted children the 10- and 11-y-old data were used. The Teacher Report Form (TRF) is the CBCL version to be completed by the child's teacher. Reference values for the Dutch population are available (14).

Self-perception profile for children (SPPC). Harter developed this self-reported instrument for measuring self-esteem or perceived competence in children (15). Self-competence in different domains is measured (scholastic and athletic competence, social acceptance, physical appearance and behavioural conduct), as well as an independent assessment of global self-worth. A Dutch translation was validated by Van Dongen-Melman et al. (16). The SPPC has been used in several studies on short stature $(17,18)$. For this study data on social acceptance and physical appearance were analysed, as children with early puberty may be less socially accepted and do not feel comfortable with their physical appearance.

Silhouette Apperception Technique (SAT). This test describes the accuracy of estimation of current and future height and was developed to study expectations of treatment with recombinant GH (19).

Nijmeegse Vragenlijst voor de Opvoedings Situatie (NVOS). This is a validated Dutch questionnaire evaluating family stress. It is completed independently by the father and the mother of a child. With the NVOS many aspects of family functioning and family stress are evaluated. Analysis was limited to four main items that were regarded to be of specific importance: (i) to what extend the family functioning is accepted or should be changed; (ii) the presence of problems; and (iii) whether the parents are able to deal with problems. For these items a higher score indicates increased family stress. (iv) A general assessment of family functioning is expressed in the "satisfaction" item: the higher the score, the more satisfied the parent is. The NVOS was used in earlier studies in children with precocious puberty and validated for the Dutch population (20).

Intelligence quotient (IQ). This was assessed with the short form of the Wechsler Intelligence Scale for children.

Standardized structured interview on signs of early puberty and expected aspects of treatment. The structured interviews addressed issues on the duration of pubertal signs and the impact on the child, as well as expected difficulties or problems with treatment, injections or endurance.

\section{Data collection during and after treatment}

The T2 data collection was performed at the end of the $3 \mathrm{y}$ treatment period. Identical instruments to those used 
Table 1. Patient characteristics at the start of treatment.

\begin{tabular}{lccr}
\hline & Group A $(13$ girls $)$ & Group B (14 girls) & Boys $(n=3)$ \\
\hline Chronological age $(\mathrm{y})$ & $9.7 \pm 0.9$ & $9.6 \pm 0.9$ & $11.0 \pm 0.6$ \\
Age on arrival $(\mathrm{mo})^{\mathrm{a}}$ & $3.0(1.0-84.0)$ & $7(1.0-51.0)$ & $2.0(1.5-14.0)$ \\
Height $(\mathrm{cm})$ & $133.6 \pm 8.4$ & $135.1 \pm 5.7$ & $132.0 \pm 2.8$ \\
Bone age $(\mathrm{y})$ & $10.8 \pm 1.1$ & $11.6 \pm 0.8$ & $10.5 \pm 1.4$ \\
Predicted adult height $(\mathrm{cm})$ & $149.3 \pm 5.7$ & $146.8 \pm 4.8$ & $166.1 \pm 6.9$ \\
\hline
\end{tabular}

Data are means $\pm \mathrm{SD}$

${ }^{a}$ Median (range).

in the $\mathrm{T} 1$ assessment were used, except for the structured interviews. During treatment there was an evaluation of the treatment using a structured questionnaire for the parents and the child, asking about endurance and burden of treatment and the perceived meaningfulness of the treatment.

\section{Statistics}

The observed data were compared with known normative data using one-sample $t$-tests. Non-parametric (Wilcoxon signed rank) tests with paired data were used for the comparison between $\mathrm{T} 1$ and $\mathrm{T} 2$ values. Because of the small numbers of patients no extensive statistical methods were applied to the data.

The protocol was approved by the local medical ethics committees and by the Dutch National Board on Medical Research (KEMO). Written informed consent was obtained from all participants in the study.

\section{Results}

Some baseline characteristics of the patients are shown in Table 1. The results reported are for the girls, unless otherwise stated. No significant differences were present between group A and group B at baseline.

During treatment, one girl dropped out from group A. The data collection was incomplete for some parents who refused to complete the questionnaires, mainly as they believed that there were no problems with the child or they judged their family situation to be without problems.

The results of the height data are described separately (Mul et al., submitted). In brief, a mean increase in predicted adult height was observed in both groups, with a significantly higher increase in group B than in group A (10.1 vs $5.7 \mathrm{~cm})$.

\section{Emotional and behavioural problems}

The CBCL scores from the study group were compared with the known age-matched norms for Dutch girls as well as with the norms for adopted girls in The Netherlands. Furthermore, scores on T1 and T2 were compared. Results are shown in Table 2. Data are presented as means $\pm \mathrm{SD}$. There were no significant differences between the mean values at $\mathrm{T} 1$ and $\mathrm{T} 2$ compared with the norms of either adopted or nonadopted children in The Netherlands. The decrease in total problem score and internalizing and externalizing scores did not reach statistical significance.

Total problem score in group A (GnRHa alone) was significantly higher than in group $\mathrm{B}(\mathrm{GnRHa}+\mathrm{GH})$ at T1 assessment: $25.31 \pm 19.98$ and $11.42 \pm 11.08$ in groups $\mathrm{A}$ and $\mathrm{B}$, respectively $(p<0.05)$. All other measurements at T1 and T2, described in Table 2, did not differ significantly between groups $\mathrm{A}$ and $\mathrm{B}$. In group B the total problem score was significantly lower than for the Dutch girls (T1, 11.42 \pm 11.08 ; $\mathrm{T} 2,13.08 \pm 8.30 \quad$ vs $19.18 \pm 14.82, \quad n=12, \quad$ both $p<0.05$ ), but not compared with the adopted girls. No significant correlations were present between changes in the CBCL scores and the increase in predicted adult height during the study period.

In 14 girls $\mathrm{T} 1$ and $\mathrm{T} 2$ scores of the TRF were available. No significant differences were observed between $\mathrm{T} 1$ and $\mathrm{T} 2$. Total problem score, and internalizing and externalizing scores decreased according to the age-specific pattern.

\section{Self-perception}

The mean scores in $\mathrm{T} 1$ and $\mathrm{T} 2$ for girls for general selfworth were not significantly different from those of the Dutch references (16). Mean scores for physical appearance decreased from $\mathrm{T} 1$ to $\mathrm{T} 2$, and social

Table 2. Results of the Child Behaviour Checklist (CBCL).

\begin{tabular}{|c|c|c|c|c|}
\hline & $\begin{array}{c}\mathrm{T} 1 \\
(n=25)\end{array}$ & $\begin{array}{c}\mathrm{T} 2 \\
(n=23)\end{array}$ & $\begin{array}{l}\text { Adopted norm, girls } 10 \text { and } 11 \mathrm{y} \\
\qquad(n=235)\end{array}$ & $\begin{array}{l}\text { Dutch norm, girls } 4-11 \mathrm{y} \\
\qquad(n=593)\end{array}$ \\
\hline Total problem score & $18.64 \pm 17.49$ & $15.22 \pm 13.01$ & $18.14 \pm 17.12$ & $19.18 \pm 14.82$ \\
\hline Internalizing score & $5.68 \pm 5.36$ & $4.22 \pm 4.98$ & $4.98 \pm 5.49$ & $5.16 \pm 5.02$ \\
\hline Externalizing score & $5.72 \pm 5.98$ & $4.70 \pm 5.16$ & $5.48 \pm 6.35$ & $6.04 \pm 5.57$ \\
\hline
\end{tabular}

Data are means $\pm \mathrm{SD}$. 
Table 3. Scores on the Self-perception Profile for Children (SPPC).

\begin{tabular}{lccc}
\hline & T1 score $(n=23)$ & T2 score $(n=23)$ & Norm (girls) \\
\hline General self-worth & $3.34 \pm 0.72$ & $3.25 \pm 0.69$ & 3.19 \\
Physical appearance & $3.12 \pm 0.62$ & $2.81 \pm 0.85$ & 3.03 \\
Social acceptance & $3.22 \pm 0.71$ & $3.43 \pm 0.49^{* *}$ & 3.02 \\
\hline
\end{tabular}

Data are means \pm SD.

$* * p<0.01$ compared with norm.

acceptance values increased. The score for social acceptance at T2 was significantly higher than the reference population $(p<0.01)$. There was no significant difference in the T1 or T2 scores for general selfworth, physical appearance and social acceptance between children with and without $\mathrm{GH}$ addition (Table 3).

No significant correlation was present between the change in SPCC variables and the increase in predicted adult height.

\section{Expectations of treatment}

The Silhouette Apperception test before the start of treatment showed that the parents did not expect an increase in height percentile from the estimated actual height to adult stature. The children, however, expected an increase from about the 30th percentile to about the 60 th percentile by the time they reach adult stature $(p<0.001)$. At the T2 assessment, the expectations for

Table 4. Estimated actual and future height expressed in height percentiles in the study group for children and parents.

\begin{tabular}{|c|c|c|c|c|}
\hline & \multicolumn{2}{|c|}{$\mathrm{T} 1$} & \multicolumn{2}{|c|}{$\mathrm{T} 2$} \\
\hline & $\begin{array}{l}\text { Child } \\
(n=30)\end{array}$ & $\begin{array}{l}\text { Parent } \\
(n=29)\end{array}$ & $\begin{array}{l}\text { Child } \\
(n=29)\end{array}$ & $\begin{array}{l}\text { Parent } \\
(n=26)\end{array}$ \\
\hline \multicolumn{5}{|c|}{ Actual height } \\
\hline $\mathrm{P}_{3}$ & 12 & 14 & 5 & 11 \\
\hline $\mathrm{P}_{25}$ & 8 & 9 & 13 & 8 \\
\hline $\mathrm{P}_{50}$ & 4 & 6 & 8 & 4 \\
\hline $\mathrm{P}_{75}$ & 4 & - & 2 & 3 \\
\hline$P_{97}$ & 2 & - & 1 & - \\
\hline \multicolumn{5}{|c|}{ Future height } \\
\hline $\mathrm{P}_{3}$ & 1 & 10 & 1 & 9 \\
\hline $\mathrm{P}_{25}$ & 5 & 14 & 7 & 13 \\
\hline $\mathrm{P}_{50}$ & 10 & 4 & 6 & 2 \\
\hline $\mathrm{P}_{75}$ & 10 & 1 & 15 & 2 \\
\hline $\mathrm{P}_{97}$ & 4 & - & - & - \\
\hline
\end{tabular}

future height were less optimistic in the children than at start of treatment, but the $p$-value was still $<0.01$ compared with the estimation of present height. Data for boys and girls are summarized in Table 4.

Assuming a score of $\geq \mathrm{P}_{50}$ to indicate overestimation of height, the proportion of children overestimating future height was $80 \%$ at $\mathrm{T} 1$ and $72 \%$ at $\mathrm{T} 2$; for parents the respective percentages were $17 \%$ and $15 \%$.

\section{Family stress}

The NVOS scores from the mothers were used and studied for the whole group, as a considerable number of fathers did not complete the questionnaire. A summary of the main parameters is given in Table 5 . The first three mentioned items out of four listed in the table show lower values in the study group than in mothers from the general Dutch population. The higher the score on "satisfaction" the more the mother is satisfied about the rearing situation in the family. No significant differences were found between children with and without the addition of $\mathrm{GH}$ with respect to the studied NVOS items.

\section{Intelligence}

The IQ levels for the whole group decreased significantly, from $100.2(12.7)$ at $\mathrm{T} 1$ to $93.1(10.5)$ at $\mathrm{T} 2$ $(p=0.002)$, but this was not clinically relevant. A comparable significant decrease was present in both groups. There were no significant differences between groups A and B at T1 or T2 (Table 6).

\section{Structured interviews}

Eighty percent of the children reported that their classmates did not treat them differently from others, while $13 \%$ ( 4 children) reported being bullied for any reason. With regard to the treatment at $\mathrm{T} 1,20 \%(6 / 22)$

Table 5. Scores on the Nijmeegse Vragenlijst voor de Opvoedings Situatie (NVOS; family stress).

\begin{tabular}{llrr}
\hline & $\mathrm{T} 1(n=26)$ & $\mathrm{T} 2(n=22)$ & Dutch norms \\
\hline Acceptance & $1.11 \pm 0.18^{* * *}$ & $1.22 \pm 0.33^{*}$ & $1.40 \pm 0.49(n=234)$ \\
Able to deal with problems & $1.38 \pm 0.33^{* * *}$ & $1.52 \pm 0.31^{* *}$ & $1.71 \pm 0.56(n=234)$ \\
Having problems & $1.45 \pm 0.41^{* * *}$ & $1.55 \pm 0.39^{* * *}$ & $1.94 \pm 0.60(n=234)$ \\
Satisfaction & $4.09 \pm 0.65$ & $3.80 \pm 0.79$ & $3.86 \pm 0.58(n=167)$ \\
\hline
\end{tabular}

Data are means $\pm \mathrm{SD}$.

$* p<0.05, * * p<0.01, * * * p<0.001$, all compared with norm. 
Table 6. Results of intelligence quotient (IQ) subtests (25 paired observations).

\begin{tabular}{llll}
\hline & & \multicolumn{3}{c}{ Performance } \\
& Verbal score & \multicolumn{1}{c}{ score } & \multicolumn{1}{c}{ Total IQ } \\
\hline Whole group T1 & $9.08 \pm 2.96$ & $11.48 \pm 4.04$ & $100.2 \pm 12.7$ \\
& $(3-19)$ & $(6-26)$ & $(77-138)$ \\
Whole group T2 & $8.04 \pm 1.92$ & $9.28 \pm 3.08$ & $93.1 \pm 10.5$ \\
& $(5-14)$ & $(5-15)$ & $(80-123)$ \\
Difference T1-T2 & ns & 0.001 & 0.002 \\
\hline
\end{tabular}

Data are means $\pm \mathrm{SD}$ (range).

ns: not significant.

of the children expected that it would be difficult to continue the monthly injections during the whole treatment period, while the parents expected only minor or no problems.

When the children $(n=21)$ were asked to estimate pain from injections (on a scale from much pain to no pain) the majority expected "some pain" and only one child expected "pain" or "much pain". In parents $(n=22)$ the distribution was shifted towards pain: 8 expected "some pain" and 11 "pain" or "much pain". The answers of parents to the question regarding the additive effect of $\mathrm{GH}$ administration indicated that they expected more gain from $\mathrm{GH}$ administration than the children did.

\section{Discussion}

When discussing and interpreting the results of this study one should acknowledge the limitations of the study with regard to sample size and the lack of an untreated control group. Furthermore, the several factors involved, for example the adoption status, early puberty and short stature, make interpretation even more difficult.

In contrast to the initial hypothesis, adopted children with early puberty and low predicted adult height did not differ markedly from adopted or non-adopted children with regard to emotional and behavioural problems or self-perception. Their parents did not exhibit higher scores on variables of family stress.

The results for the parents at $\mathrm{T} 1$ revealed that they are competent and realistic people, able to cope with the presence of early puberty in their adopted child. This is in line with the literature on families with adopted children or children born after reproductive techniques in which the quality of upbringing was shown to be better than in children born after normal conception (21). This quality may be explained by the high socioeconomic status of adoption parents and the fact that they are selected on parenting capacities before adoption.

From an analysis of the CBCL data, the children in this study population did not show more behavioural or emotional problems than their age- and sex-matched adopted peers. The reason for this may be that most children in the study group had only experienced their secondary sexual maturation characteristics, e.g. breast development, for a short period, which had not yet led to embarrassment or bullying. The pubertal growth spurt may result in the actual height being experienced positively by the child, as it may bring the height closer to that of the child's peers. Another reason could be the positive attitude of the parents to their children, emphasizing that being different from peers can be labelled positively. Many people believe the early pubertal development to be normal for children adopted from developing countries. In addition, the children are strongly supported by their parents in coping with their early pubertal development. Similar factors could be used to explain the results from the SPPC social acceptance subscale demonstrating that adopted children feel themselves to be accepted by their peers, even in the presence of signs of early puberty making them more different from their peers. The difference in total problem scores between groups $\mathrm{A}$ and $\mathrm{B}$ at $\mathrm{T} 1$ cannot be explained by differences in auxological variables at baseline.

In the longitudinal analysis CBCL scores showed a tendency to decrease in the total problem score and subscales for internalizing and externalizing problem scores. The decrease was comparable with the lower scores in older children in the reference population. Apparently, the treatment did not contribute to increases in problem behaviour or emotional problems, as one may expect when accounting for the intensity of treatment. This can be explained by the positive attitude of parents and the fact that a lot of attention is paid to the children in the research setting. Furthermore, the relationship between the parents and the adopted child was described by the parents as close (22). The major intervention of suppressing pubertal development, causing regression or arrest of pubertal development, may decrease problematic behaviour (4) or at least prevent a further increase in problems.

Early or precocious puberty leads to elevated CBCL scores on the internalizing syndrome (withdrawal and anxious/depressed) up to $2 \mathrm{y}$ after the start of treatment (4). The present results did not confirm this observation; perhaps because the age at the start of treatment was relatively high compared with reports in children with precocious puberty. No association was found between idiopathic precocious puberty and long-term severe psychopathology; however, precocious puberty in girls has been reported to be associated with a long-term risk of minor psychopathology $(5,23)$. With respect to psychosexual development, early pubertal development was associated with earlier, but not extremely advanced psychosexual development $(5,23)$. During treatment with GnRHa problematic behaviour and functioning decreased slightly, particularly in the girls showing regression of breast development (4). In the present 
study population regression of the signs of puberty was observed in all patients.

The most remarkable finding in the longitudinal assessment of SPPC was the relative increase in the score for social acceptance. Several factors could play a role: the regression of pubertal signs brings the child back into line with the age-matched peers, children may feel that treatment makes them more "normal" now and in the future, and the decreasing trend in emotional or behavioural problems may improve acceptance in the peer group.

It is difficult to demonstrate quantitatively to what extent children suffer from early puberty or short stature, because of a lack of standardized instruments. Therefore, the indication for growth-promoting treatments such as performed in this trial is hard to sustain, as was demonstrated in the case of children with short stature (24). However, one can assess parents' and children's expectations of treatment. Using the SAT the perceived current height and the expected height after treatment were evaluated. The scores from the SAT showed that the expectations of the children with regard to future height were still positive at the end of treatment, while those in the parents did not change during the treatment period. This indicates the limited capacity of the children to predict and estimate figures in the future, while they are able to estimate their own current height in comparison to their peers. Parents did not have unrealistic expectations of the effect of treatment, probably owing to the thorough information procedure before the informed consent was given. In contrast, the children expected to be considerably taller at the end of treatment than they were at the moment of starting treatment. In children with short stature about $60 \%$ of the girls had unrealistic expectations of their future height $\left(\geq \mathrm{P}_{50}\right)$, compared with about one-third in parents (25).

With regard to family stress, the presence of early puberty and expected short stature did not increase stress to levels above normal. On the contrary: family stress was even significantly lower on the studied subitems. The treatment did not give rise to family stress above the normal limits. It is likely that the study dealt with stable families, which were already used to handling difficulties and able to manage these (26). Thereby, in general, the socioeconomic and educational level of parents of adopted children is relatively high. One can conclude that, as in children from in vitro fertilization (IVF) or KID procedures, the parents are competent in dealing with the problems of their children. However, 1 y postpartum, IVF parents reported lower self-esteem and IVF mothers saw their children as more vulnerable and "special" compared with controls (27). They often mentioned that their motivation was based on the idea of precluding future regret for not having tried every possible treatment option available. This could theoretically lead to overprotection with possible adverse effects on the child. In a quantitative analysis of motivation for treatment it was concluded that the vast majority of parents was adequately motivated (Mul et al., submitted). In the present study population the delay between the start of pubertal development and the start of treatment was not as long as in the study by Xhrouet-Heinrichs et al. (4), which was interpreted as a result of a cultural taboo about sexuality and pubertal development. The present authors' experience does not indicate that such a taboo was present in this population. It is likely that the early occurrence of puberty in adopted children is regarded as normal for this group of children.

The background variables for the adjustment of adopted children were described in the early 1970 s by Bohman (28) as relatively independent of each other. Verhulst et al., however, found that several background parameters placed the child at increased risk for later maladjustment, but even in the presence of such variables the majority of adopted children functioned quite well (29). The assessments performed in the present study indicated normal functioning by the children, and early puberty and/or short stature did not seem to influence this negatively; however, they still have to go through puberty and adolescence, which may be a vulnerable period for some adopted children with respect to identity and relations with parents (9). In addition, when puberty progresses in peers, the feeling of being small may be enforced by the magnitude of the growth spurt in Dutch boys and girls.

The results on IQ measurements in children with precocious puberty showed elevated scores, with higher verbal than performance scores, and this was interpreted as a possible effect of sex steroids, especially on the left hemisphere $(4,30)$. The initial total IQ score in this group was not different from normal-comparable with the data of Xhrouet-Heinrichs et al. (4) - and a decrease of about 7 points was observed during the treatment period. Although significant, doubts exist about the clinical relevance of this decrease. One hypothesis for the decrease in verbal IQ scores is that withdrawal of exposure of the brain to sex steroids brings the child back into a more age-appropriate IQ range. The lower verbal scores in this group, which was in contrast to results in girls with central precocious puberty, could be explained by the adoption status of the children; as in other children from foreign backgrounds, it is known that verbal intelligence is lower than in children born in their own country. In primary school, mathematics, which is part of verbal IQ, was problematic in adopted children, especially in boys. The authors concluded that a deficient development of visual-spatial organization and, to a lesser extent, poorer concentration, may be due to the lower achievements in mathematics rather than to intelligence or fluency.

The observation that there were no consistent differences between groups A and B suggests that in early puberty the addition of GH does not contribute to development in either a protective or negative direction 
and that pubertal arrest is the main intervention in children with early puberty.

In conclusion, in adopted children with early puberty and predicted short stature the levels of emotional and behavioural problems, self-perception and family stress did not differ significantly from the population means. The treatment with GnRHa, either alone or in combination with $\mathrm{GH}$, did not increase emotional and behavioural problems or family stress, nor did it decrease the children's self-perception.

Acknowledgements.-Pharmacia \& Upjohn AB, Stockholm Sweden, and Ferring, The Netherlands, financially supported the study.

\section{References}

1. Bourguignon JP, Gerard A, Alvarez Gonzales ML, Fawe L, Franchimont P. Effects of changes in nutritional conditions on timing of puberty: clinical evidence from adopted children and experimental studies in the male rat. Horm Res 1992; 38 Suppl 1: 97-105

2. Virdis R, Street ME, Zampolli M, Radetti G, Pezzini B, Benelli $\mathrm{M}$, et al. Precocious puberty in girls adopted from developing countries. Arch Dis Child 1998; 78: 152-4

3. Proos LA, Hofvander Y, Tuvemo T. Menarcheal age and growth pattern of Indian girls adopted in Sweden I menarcheal age. Acta Paediatr Scand 1991; 80: 852-8

4. Xhrouet-Heinrich s D, Lagrou K, Heinrichs C, Craen M, Dooms L, Malvaux P, et al. Longitudinal study of behavioral and affective patterns in girls with central precociou s puberty during long-acting triptorelin therapy. Acta Paediatr 1997; 86: 808-15

5. Ehrhardt AA, Meyer-Bahlburg HFL. Psychosocial aspects of precociou s puberty. Horm Res 1994; 41 Suppl 2: 30-5

6. Lagrou K, Xhrouet-Heinrich s D, Bourguignon JP. Deviations in growth and pubertal development and their treatment: how consistent are patient's and physician 's outlooks? In: Eiholzer U, Haverkamp F, Voss L, editors. Growth, stature, and psychosocia 1 well-being. Seattle, WA: Hogrefe \& Huber, 1999: 131-7

7. Sigurjonsdottir TJ, Hayles AB. Precocious puberty. A report of 96 cases. Am J Dis Child 1968; 115: 309-21

8. Verhulst FC, Althaus M, Versluis-den Bieman HJ. Problem behavior in international adoptees: I. An epidemiological study. J Am Acad Child Adolesc Psychiatry 1990; 29: 94-103

9. Versluis-den Bieman HJ, Verhulst FC. Self-reported and parent reported problems in adolescent international adoptees. J Child Psychol Psychiatry 1995; 36: 1411-28

10. Roede MJ, Wieringen JC van. Growth diagrams 1980. Netherlands third nation-wide survey. Tijdschr Soc Gezondheidszor g 1985; 63 Suppl: 11-32

11. Achenbach TM. Manual for the CBCL/4-18 and 1991 profile. Burlington, VT: University of Vermont Department of Psychiatry, 1991

12. Verhulst FC, Akkerhuis GW, Althaus M. Mental health in Dutch children: (I). A cross-cultura 1 comparison. Acta Psychiatr Scand Suppl 1985; 323: 1-108

13. Verhulst FC, Versluis-Den Bieman HJM. Comparison between adopted and non-adopte d children (Dutch). In: Buitenlandse adoptiekinderen. Assen: Van Gorcum, 1989: 27-48 (in Dutch)

14. Verhulst FC, Ende J van der, Koot HM. Handleiding voor de Teacher's Report Form (TRF) (User's Guide for TRF). Rotterdam: Department of Child and Adolescent Psychiatry, Sophia Children's Hospital, 1997 (in Dutch)

15. Harter S. The perceived competence scale for children. Child Dev 1982; 53: 87-97

16. Van Dongen-Melman JEWM, Koot HM, Verhulst FC. Crosscultural validation of Harter's self-perceptio n profile for children in a Dutch sample. Educ Psychol Measure 1993; 57: 739-53

17. Zimet GD, Cutler M, Litvene M, Dahms W, Owens R, Cutler L. Psychological adjustment of children evaluated for short stature: a preliminary report. J Dev Behav Pediatr 1995; 16: 264-70

18. Gilmour J, Skuse D. Peer and self-perception of children with short stature - the role of cognition. In: Eiholzer U, Haverkamp F, Voss L, editors. Growth, stature, and psychosocial well-being . Seattle, WA: Hogrefe \& Huber, 1999: 37-46

19. Erling A, Wiklund I, Albertsson-Wikland K. Prepubertal children with short stature have a different perception of their well-being and stature than their parents. Qual Life Res 1994; 3: 425-9

20. Robbroeckx LMH, Van der Schot-de Jong LWA, Otten BJ. Family stress in parents of girls with early puberty. Kind Adolesc 1990; 4: 180-92 (in Dutch)

21. Golombok S, Cook R, Bish A, Murray C. Families created by the new reproductive technologies: quality of parenting and social and emotional development of the children. Child Dev 1995; 66: 285-98

22. Tizard B. Intercountry adoption: a review of the evidence. J Child Psychol Psychiatry 1991; 32: 743-56

23. Ehrhardt AA, Meyer-Bahlburg HF. Idiopathic precocious puberty in girls: long-term effects on adolescent behavior. Acta Endocrinol Suppl (Copenh) 1986; 279: 247-53

24. Guyda HJ. Four decades of growth hormone therapy for short children: what have we achieved? J Clin Endocrinol Metab 1999; 84: 4307-16

25. Huisman J. Medisch psychologische bijdragen aan nieuwe behandelingswijze $n$ in de kindergeneeskunde. Thesis, Free University, Amsterdam, 1993 (in Dutch)

26. Ferguson DM, Lynskey M, Horwood LJ. The adolescent outcomes of adoption: a 16-year longitudinal study. J Child Psychol Psychiatry 1995; 36: 597-615

27. Gibson FL, Ungerer JA, Tennant CC, Saunders DM. Parental adjustment and attitudes to parenting after in vitro fertilization. Fertil Steril 2000; 73: 565-74

28. Bohman M. A study of adopted children, their background, environment and adjustment. Acta Paediatr Scand 1972; 61: 90-7

29. Verhulst FC, Althaus M, Versluis-den Bieman HJM. Damaging backgrounds: later adjustment of international adoptees. J Am Acad Child Adolesc Psychiatry 1992; 31: 518-24

30. Galatzer A, Beth-Halachmi N, Kauli R, Laron Z. Intellectual function of girls with precocious puberty. Pediatrics 1984; 74: 246-9

Received Aug. 28, 2000; revisions received Dec. 8, 2000 and May 14, 2001; accepted May 15, 2001 